\title{
Economic Growth- Female Labour Supply Nexus: A Dynamic U-Shaped Perspective for Pakistan
}

\author{
Nooreen Mujahid \\ Department of Economics, University of Karachi \\ PO box 75270, Main University Rd, Karachi, Karachi City, Pakistan \\ Nargis \\ MPhil Research Scholar \\ Department of Economics, University of Karachi \\ PO box 75010, Gulshan-e-Hadeed, Phase 1, Karachi Pakistan \\ Muhammad Noman* \\ Senior Lecturer \\ Department of Finance and Economics, Muhammad Ali Jinnah University \\ PO box 75080, Malir, Karachi, Pakistan \\ Musarrat Shamshir \\ Faculty of Management Sciences, Greenwich University \\ DK-10,38Steet, Darakshan, Phase VI, Defence Housing Authority, Karachi, Pakistan
}

\begin{abstract}
The developing and fast growing economy of Pakistan is going through the process of structural and demographic change. Hence, the contemporary pattern of economic growth demands both males and females to contribute in the labour market activities. Therefore, the idea of the study revolves around the fact that improvement in economic conditions of women would motivate them to participate in the labour market. The prime concern of the study is to investigate a U-shaped dynamic nexus between variables of economic growth and female labour supply in the context of Pakistan for the time span of 1990-2017. The study has employed the dynamic perspective through employing the ARDL technique. This specific method has assessed to trace out both long and short run relationship between core variables. It is conclude that the U-shaped dynamic association between economic growth and female labour supply is prominent for the economy of Pakistan. Considering the findings of the study, a few doable policy recommendations are also recommended.
\end{abstract}

Keywords: Economic development, female labour supply, U-shaped hypothesis, dynamic analysis, ARDL.

DOI: $10.7176 / \mathrm{JESD} / 10-8-07$

Publication date: April $30^{\text {th }} 2019$

\section{Introduction}

The predominant hypothesis about the long-term relationship between economic development and female labour supply is the U-shape hypothesis. The hypothesis broadly states that during the early stages of economic development, labour supply of females dips as the economy structurally transits from agriculture to industrial sector. However, it surges in later phases of growth and development with modern economy, low fertility rates and high literacy rates (Psacharopoulos \& Tzannatos, 1989, Boserup, 1970, Durand, 1975).

Considering the advanced perspective of the hypothesis, Goldin $(1994,1995)$ explored that the U-shape nexus between economic growth and female labour supply in developing economies is weak due to more female participation in the agrarian economy. The women in such deprived economies are thus restricted to field work; childcare in domestic tasks; and low paid jobs. Moreover expansion in the manufacturing sector, new technologies, rise in family incomes are also prominent to squeeze the economic activity and participation of females in such economies (Mammen and Paxson, 2000).

Correspondingly, the developing and yet most fast growing economy of Pakistan has also gone through such structural and demographic change. The economy is also witnessing a demographic dividend where the proportion of young, energetic and productive workforce is surging. The demographics of the economy reveal that women in Pakistan constitute more than half of the population (101.32) with 48 percent of literacy rate (Economic Survey of Pakistan, 2017-18) and 20.1 percent of refined labour force participation rate (Labour Force Survey of Pakistan, 2017-18). Precisely, this scenario has in turn created an opportunity for women to play their part more effectively as productive assets in the economic activity.

Thus, the contemporary pattern of economic growth of the country demands both men and women to contribute in the labour market activities. Meanwhile, it seems convenient to assume that this may further tend to enhance economic development through their more representation in manufacturing and services sector and 
improvement in women's education. On the whole, there is a possibility of causality between various stages of economic progress and female labour supply.

\subsection{Objectives of the Study}

The idea of the study revolves around the fact that better economic conditions motivate women to enter into the labour market for earnings. The prime concern of the study is to investigate the U-shaped dynamic nexus between economic growth and female labour supply in the context of Pakistan for the time span of 1990-2017.Moroever, the dynamic perspective is employed the Auto Regressive Distributive Lag (ARDL) technique. This specific technique assesses to trace the both long run and short run association between economic growth and female labour supply.

\section{Theoretical and Empirical Review of Literature}

Klasen (2018) investigated heterogeneous trends in the participation rates of female and reported inconsistent trends of the traditional U-shaped hypothesis for women at regional level. The study pointed that these trends were strong in Latin America, moderate in Middle East and quiet weak in South Asia. These results could be attributed to the interplay of preliminary circumstances, economic arrangements, structural transformation, and tenacious gender customs and values in developing economies.

Khaliq et al., (2017) observed the node between the female labour force participation and economic growth for Pakistan. The authors employed data for the time span of 1990-2014 and applied the Johensen and ECM methods. The result of the study endorsed that both variables were linked significantly in both long term and short term confirming the U-shaped hypothesis. The authors also concluded that low level of employed females in the labour market would have a direct impact on economic activity of Pakistan.

Lechman and Kaur (2015) explored recent tendency of economic growth and female labor supply. The authors collected a sample of 162 economies over the time span of 1990-2012 employing Quadratic Panel Regressions. The findings of the study asserted a U-shape association between the two core variables, however, there were considerable cross-economy variations. Furthermore, the hypothesis had not been verified (positively) in low-income economies of the sample.

Verme (2014) tested the U-shaped hypothesis for the economies of Middle East and North Africa (MENA) covering the data for the period of 1990-2012. The author applied the Nonparametric Estimation technique and approved that the hypothesis did not only hold globally but also for the region of MENA. The study fundamentally attributed the consistency of hypothesis with other relevant aspects such as education, share in agriculture (value added) and fertility rates of women. Considering the consistency of the data, the study also claimed that the economies of MENA had outperformed other economies showing more success in terms of linking economic growth and female labour supply.

Nooreen et al., (2013) explored the U-shaped nexus in Pakistan through the proxies of Gross Domestic Product (GDP) per capita and labour force participation rate for females. The study confirmed a U-shaped nexus between economic progress and women labour force participation considering the time period of 1980- 2011 through Johansen Cointegration technique. Moreover, the study stressed that enhancement in education attainment and economic activity would further accelerate female participation in the labour market.

Sanjukta (2010) reconsidered the 172 economies of South Asia and South East Asia to test the U-shaped postulates from 1990 to 2007. The study observed a firm U-Curved, meanwhile both regions were on the plummeting portion of the curve. Besides, South Asian economies were at more below the curve while the economies of other region were marginally beyond the curve. Furthermore, Pakistan stood the lowest in term of female labour force participation as compare to economies of Vietnam as well as Cambodia.

Cakir (2008) focused on the effects of the growth of the economy on female participation in the labour market employing data span from 1980 to 2000 for Turkey. The study incorporated five different econometric models to quantity diverse elements of women labour supply. The study concluded that the economy of Turkey was going through the dipping segment of U-curve yet the data estimates predicted that the economy would earlier move to the rising segment of U-shaped curve. The outcomes of the study were in line with the previous study of Tansel (2002).

Fatima and Sultana (2009) determined the U shaped arrangement between economic development and female labour supply employing Fixed Effect model. The cross sectional data spans include years of 1992-93, 1996-97 and 2001-2002.The authors incorporated household expenditures (fuel consumption) as a proxy of economic development due to lack of data availability on GDP at the provincial level. The findings of the study revealed that the hypothesis was consistent with the marital status, education, share in sectors, wages and rate of unemployment of women. These outcome had confirmed that high economic growth was enhancing female participation in the labor force.

Mammen and Paxson (2000) explored the U-shaped evidence in favor of 90 countries. The author analyzed the cross country data for the years of 1970,1975, 1980 and 1985.The authors found that economic growth in both 
developed and the deprived economies was equally contributing in increasing participation rates of females.

There is also another yet limited strand of literature that argues that U-shaped prodigy is not a genuine trend in developing economies (Schnabel \& Wegner, 2008; Lind and Mehlum, 2007).

\section{Methodology}

\subsection{Model}

The empirical model of U-shaped Hypothesis as follows:

\section{FLS $=\mathbf{f}\left(\right.$ GRGDP, RPCY, LOG $\left(\right.$ RPCY $\left.^{2}\right)$}

\section{Where;}

FLS $=$ Female Labour Supply

GRGDP $=$ Growth Rate of Gross Domestic Product

$\mathrm{RPCY}=$ Real Per Capita Income

$\mathrm{RPCY}^{2}=$ Non-linear term of RPCY

\subsection{Data Sources}

The study coves the time span from 1990 to 2018 and the data has been collected from the World Development Indicators (WDI).

\subsection{Estimation Strategy}

This study has used time series data, which shows trends of macroeconomic data. Therefore, the Augmented Dickey Fuller (ADF, 1979) criterion has been integrated to examine the stationarity of the variables. This is the pre-requisite to perform series analysis and to make series reliable and efficient. Moreover, this test helps to identify the appropriate methodology for the study. On the basis of ADF results, the ARDL Cointegration model has been applied to evaluate the long run association among variables.

Once long term association between development and female labour supply of the economy has been recognized then short run association between the variable has been assessed through the Error Correction Model (ECM). The econometric representation of the ECM model is as follows;

\section{ECM $=\Delta \mathrm{FLS}=\alpha+\alpha 2 \Delta \mathrm{RPCYi}+\alpha 3 \Delta \mathrm{RPCY} 2 \mathrm{i}+\alpha 3 \Delta \mathrm{GRGDPi}+\alpha 5 \mathrm{ECTt}-1+\varepsilon \ldots \ldots .(1)$}

Meanwhile, a few diagnostic tests have also been conducted to verify the require Classical Linear Regression Model (CLRM) assumptions for the empirical model. These tests include test of normality of error term, serial correlation, autoregressive conditional heteroscedasticity, white heteroscedasticity and specification of short run model.

\section{Empirical Results}

The descriptive estimates of the model are presented in Table 1. The outcomes stipulated that the entire series is distributed normally.

Table 1. Descriptive Statistics of the Model

\begin{tabular}{|l|c|c|c|c|}
\hline & FLS & GRGDP & RPCY & RPCY $^{2}$ \\
\hline Mean & 18.66069 & 4.459668 & 64948.15 & $7.44 \mathrm{E}+09$ \\
\hline Median & 17.87000 & 4.239160 & 38523.61 & $1.48 \mathrm{E}+09$ \\
\hline Maximum & 25.13000 & 8.958383 & 189630.7 & $3.60 \mathrm{E}+10$ \\
\hline Minimum & 12.51000 & 0.360726 & 8090.000 & 65448100 \\
\hline Std. Dev. & 4.146882 & 1.850779 & 57773.70 & $1.06 \mathrm{E}+10$ \\
\hline Skewness & 0.119121 & 0.251736 & 0.855723 & 1.426647 \\
\hline Kurtosis & 1.474651 & 3.328834 & 2.337952 & 3.765357 \\
\hline Jarque-Bera & 2.880002 & 0.436953 & 4.068884 & 10.54519 \\
\hline Probability & 0.236928 & 0.803743 & 0.130753 & 0.005130 \\
\hline Sum & 541.1600 & 129.3304 & 1883496. & $2.16 \mathrm{E}+11$ \\
\hline Sum of Square Deviations & 481.5056 & 95.91068 & $9.35 \mathrm{E}+10$ & $3.16 \mathrm{E}+21$ \\
\hline Observations & 29 & 29 & 29 & 29 \\
\hline
\end{tabular}

Source: Estimated by Authors

Table 2 explains that female labour supply and RPCY are stationary at first level while GRGDP is stationary at level with constant and trend terms. 
Table 2. Results of ADF Unit Root Test

\begin{tabular}{|c|c|c|c|c|}
\hline Variables & Calculated value & $\begin{array}{c}\text { Tabulated value } \\
(5 \%)\end{array}$ & $\begin{array}{c}\text { Tabulated value } \\
(10 \%)\end{array}$ & Probability* \\
\hline FLS(0) & -2.62609 & -4.32398 & -3.58062 & 0.2724 \\
\hline$\Delta($ FLS $)(0)$ & -5.0664 & -4.33933 & -3.58753 & 0.0019 \\
\hline GRGDP(5) & -3.55979 & -4.32398 & -3.58062 & 0.0522 \\
\hline$\Delta($ GRGDP)(0) & -6.97107 & -4.33933 & -3.58753 & 0.0000 \\
\hline RPCY(0) & 0.128857 & -4.32398 & -3.58062 & 0.9960 \\
\hline$\Delta($ RPCY)(0) & -5.10361 & -4.33933 & -3.58753 & 0.0017 \\
\hline LOG(RPCY2) $(6)$ & -5.34933 & -4.44074 & -3.6329 & 0.0015 \\
\hline$\Delta\{$ LOG(RPCY2) $(0)$ & -5.24178 & -4.33933 & -3.58753 & 0.0012 \\
\hline
\end{tabular}

Source: Estimated by Authors

These unit root outcomes confirmed to apply the ARDL modeling approach, hence, the output of the models are illustrated in Table 3.

Table 3. Estimates of ARDL Cointegration Analysis

\begin{tabular}{|c|c|c|}
\hline Estimated Model & \multicolumn{2}{|c|}{ FLS = f(GRGDP, RPCY, LOG(RPCY $\left.\left.{ }^{2}\right)\right)$} \\
\hline Optimal lags structure & \multicolumn{2}{|l|}{$(4,4,4,3)$} \\
\hline F-statistics & \multicolumn{2}{|l|}{8.57} \\
\hline \multirow{2}{*}{ Significant level } & \multicolumn{2}{|c|}{ Critical values $(\mathrm{T}=29)$} \\
\hline & Lower bounds, I(0) & Upper bounds, I(1) \\
\hline $10 \%$ & 2.676 & 3.586 \\
\hline $5 \%$ & 3.272 & 4.306 \\
\hline $1 \%$ & 4.614 & 5.966 \\
\hline
\end{tabular}

Source: Estimated by Authors

The Johansen Cointegration test indicates the existence of single Cointegration equation at $10 \%$ level of significance, thus the variables are cointegrated.

Table 4. Long Run Coefficients using the ARDL Approach

\begin{tabular}{|l|l|l|l|l|}
\hline Variable & Coefficient & Std. Error & t-Statistic & Prob. \\
\hline GRGDP & 0.953798 & 0.297671 & 3.204202 & 0.0185 \\
\hline RPCY & $-5.07 \mathrm{E}-05$ & $2.51 \mathrm{E}-05$ & -2.01464 & 0.0906 \\
\hline LOG(RPCY2) & 1.616085 & 0.426839 & 3.786174 & 0.0091 \\
\hline C & -13.6564 & 8.805297 & -1.55093 & 0.1719 \\
\hline
\end{tabular}

Source: Estimated by Authors

Table 4 explains that a 1 percent rise in RPCY (linear) is associated with 5.07E-05 percent decline in the dependent variable. The non-linear term of the RPCY indicates that at later stages of growth the variable changes its trend in favor of female labour supply as 1 percent increase in RPCY will enhance female labour supply up to 1.61 percent. Meanwhile, the GRGDP is positively associated with female labour supply in the model. The coefficient of GRGDP also explains positive and direct outcomes as it increases by 1 percent then female labour supply will also increase by 0.95 percent. Hence, the significant terms (linear and non-linear) of RGDP and GRGDP validates the existence of U-shaped association between female labour supply and economic development in Pakistan. 
Table 5. Estimates of ECM Model

\begin{tabular}{|l|c|c|c|c|}
\hline \multicolumn{1}{|c|}{ Variable } & Coefficient & Standard Error & t-Statistic & Probability \\
\hline $\mathrm{D}($ FLS(-1)) & 0.033896 & 0.110396 & 0.30704 & 0.7692 \\
\hline $\mathrm{D}($ FLS(-2)) & -0.164398 & 0.094782 & -1.734485 & 0.1335 \\
\hline $\mathrm{D}($ FLS (-3)) & 0.2606 & 0.09368 & 2.781806 & 0.0319 \\
\hline $\mathrm{D}($ GRGDP) & 0.01802 & 0.037291 & 0.483229 & 0.6461 \\
\hline $\mathrm{D}($ GRGDP(-1)) & -0.312248 & 0.062307 & -5.011444 & 0.0024 \\
\hline $\mathrm{D}($ GRGDP(-2)) & -0.029958 & 0.041239 & -0.726449 & 0.4949 \\
\hline $\mathrm{D}($ GRGDP(-3)) & -0.101935 & 0.03348 & -3.044655 & 0.0227 \\
\hline $\mathrm{D}($ RPCY) & 0.000298 & $3.14 \mathrm{E}-05$ & 9.493842 & 0.0001 \\
\hline $\mathrm{D}($ RPCY(-1)) & 0.000118 & $5.16 \mathrm{E}-05$ & 2.283027 & 0.0625 \\
\hline $\mathrm{D}($ RPCY(-2)) & $9.58 \mathrm{E}-05$ & $3.68 \mathrm{E}-05$ & 2.607162 & 0.0403 \\
\hline D(RPCY(-3)) & $-8.40 \mathrm{E}-05$ & $2.05 \mathrm{E}-05$ & -4.106529 & 0.0063 \\
\hline DLOG(RPCY2) & -8.447252 & 0.879081 & -9.609184 & 0.0001 \\
\hline DLOG(RPCY2 (-1)) & -6.236938 & 1.240314 & -5.028515 & 0.0024 \\
\hline DLOG(RPCY2 (-2)) & -4.198767 & 1.187695 & -3.535223 & 0.0123 \\
\hline ECT t-1 & -0.577626 & 0.068334 & -8.452987 & 0.0001 \\
\hline
\end{tabular}

Source: Estimated by Authors

Table 5 elucidates the short run estimates of the model. The ECM $\mathrm{t}_{\mathrm{t}-1}$ shows the speed of adjustment of the model from short run towards long run equilibrium path (Banerjee, et al. 1993). The coefficient of ECM $\mathrm{EM}_{\mathrm{t}-1}$ is 0.577626 which shows that the model will converge and it will achieve equilibrium in 1.73122 years. These estimates affirm the short run association of the variables in the model.

Table 6. Post Estimation Test Results of Heteroskedasticity and Serial Correlation

\begin{tabular}{|l|r|r|}
\hline Test & F-statistic & Probability \\
\hline Serial Correlation (Breusch - Godfrey LM ) & 2.179439 & 0.2694 \\
\hline Heteroskedasticity (Breusch - Pagan-Godfrey) & 1.336906 & 0.3812 \\
\hline Heteroskedasticity (Harvey) & 1.473822 & 0.3311 \\
\hline Heteroskedasticity (Glejser) & 1.969136 & 0.2055 \\
\hline Heteroskedasticity (White) & 1.851576 & 0.2290 \\
\hline
\end{tabular}

Source: Estimated by Authors; Note: Names in Bracket shows the selection criteria for Post estimation tests.

The diagnostic tests in table 6 endorse that there is no problem of heteroskedasticity and serial correlation in the model. Furthermore, the results of CUSUM and CUSUM in figure 1 depicts that model is stable as the plot of the CUSUM and CUSUM square tests do not cross upper or lower critical limit.

\section{Conclusion and Policy Implications}

This study endeavored to test the U-shaped hypothesis through considering the empirical nexus between economic development and female labour supply in Pakistan for the time span of 1990-2018. The estimates of dynamic ARDL Cointegration Model confirmed the U-shaped hypothesis with significant long run association of the core variables while short run estimates were also consistent. These empirical evaluations provide an intuition that economic strengthening of women is central to stamp out the existing deteriorating economic situation of Pakistan. This will not only further accelerate the pace of development of the economy but will also preserve women from the traditional social hitches. Hence, it is appropriate and the requirement of the economy to bridge the gap between women and men participation in the labour market. This could be conveniently achieved through an initiative to provide a break to women as per their potential with better wages and job opportunities. In this regard, a few doable policy recommendations are prescribed below:

- The think tanks of the economy ought to concentrate on escalation and refinement of gender based policies.

- The implementation of gender précised wage regulations must be eliminated and the pay gap between both the genders must be narrowed through improvement in education and skills of females.

- Women must be trained as per the requirements of manufacturing and industrial sectors which may further contribute to enhance female labour supply and overall employment rates.

- There must be more emphasis on cottage activities where the economic participation of women can certainly be augmented due to their skills.

- The government must announce child care incentives in form of subsidies specifically for the center of day care and pre-school education. This may eventually support females embolden them to contribute effectively in the economy. 


\section{References}

Ester, B. (1970). Women's Role in Economic Development. New York: St.

Cakir, O. (2008). The Relationship between Economic Development and Female Labor Force Participation within the Framework of U-Shaped hypothesis: Evidence from Turkey.

Dickey, D. A., \& Fuller, W. A. (1979). Distribution of the estimators for autoregressive time series with a unit root. Journal of the American statistical association, 74(366a), 427-431.

Durand, J. D. (1975). The labor force in economic development: An international comparison of census statistics.

Fatima, A., \& Sultana, H. (2009). Tracing out the U-shape relationship between female labor force participation rate and economic development for Pakistan. International Journal of Social Economics, 36(1/2), 182-198.

Goldin, C. (1994). The U-shaped female labor force function in economic development and economic history (No. w4707). National Bureau of Economic Research.

Goldin, Claudia. (1995). The U-Shaped Female Labor Force Function in Economic Development and Economic History, in T. Paul Schultz, ed. Investment in Women's Human Capital. Chi-cago: University of Chicago Press.

Mammen, K., \& Paxson, C. (2000). Women's work and economic development. Journal of economic perspectives, 14(4), 141-164.

Psacharopoulos, G., \& Tzannatos, Z. (1989). Female labor force participation: An international perspective. The World Bank Research Observer, 4(2), 187-201.

Chaudhuri, S. (2010). Women's empowerment in South Asia and Southeast Asia: A comparative analysis.

Tansel, A. (2002). Economic development and female labor force participation in Turkey: Time-series evidence and cross-section estimates. METU/ERC Working Paper, $(02 / 3)$.

Verme, P. (2014). Economic development and female labor participation in the Middle East and North Africa: a test of the U-shape hypothesis. The World Bank.

Klasen, S. (2018). What explains uneven female labor force participation levels and trends in developing countries? (No. 246). Courant Research Centre: Poverty, Equity and Growth-Discussion Papers.

Lechman, E., \& Kaur, H. (2015). Economic growth and female labor force participation-verifying the Ufeminization hypothesis. New evidence for 162 countries over the period 1990-2012. New evidence for, 162, 1990-2012.

Khaliq, A., Khan, D., Akbar, S., Hamayun, M., \& Ullah, B. (2017). Female Labor Market Participation and Economic Growth: The Case of Pakistan. Journal of Social Science Studies, 4(2), 217-230.

World Bank Group. (2017). World Development Indicators 2017. World Bank.

Economic Survey of Pakistan 2017-18

Schnabel, C., \& Wagner, J. (2008). Union membership and age: the inverted U-shape hypothesis under test. Retrieved from repec.iza.org/dp3842.pdf

Lind, J. T. and Mehlum, H. (2007). 'With or Without U? - The appropriate test for a U shaped relationship. Munich Personal RePEc Archive MPRA Paper No. 4823. Retrieved from http://mpra.ub.uni-muenchen.de/4823/]

Mujahid, N., Muhammed, S. D., \& Noman, M. (2013). Economic Growth-Women Labour Force Participation Nexus: An Empirical Evidence for Pakistan. Developing Countries Studies, 3(3), 12-23.

Banerjee, A., Dolado, J. J., Galbraith, J. W., \& Hendry, D. (1993). Co-integration, error correction, and the econometric analysis of non-stationary data. OUP Catalogue.

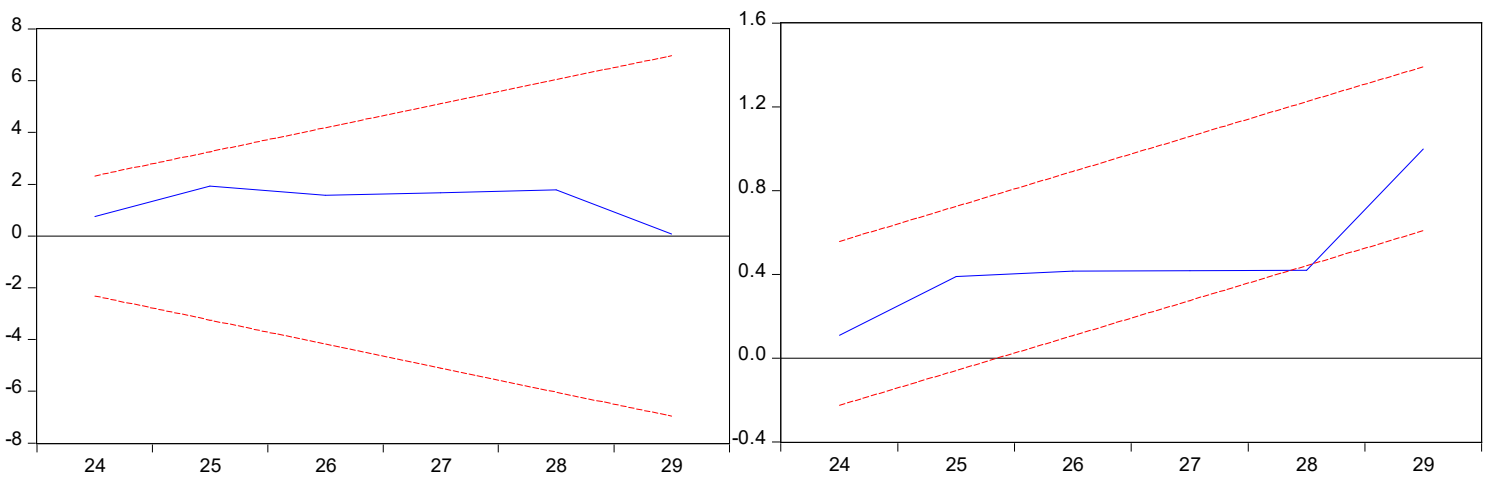

- CUSUM ---- 5\% Significance $\quad$ - CUSUM of Squares ----- 5\% Significance

Figure 1. Plot 1 and 2 Plot of Cumulative Sum and Cumulative Sum Square of Recursive Residuals Source: Illustrated by Authors 